Research article

Open Access

\title{
Influence of Baicalin on Alveolar Bone Resorption in Rat Experimental Periodontitis
} \author{
Yue Chen ${ }^{1}$, Zhi-Fen Wu ${ }^{*}$, Lian-Jia YANG ${ }^{2}$ \\ 1 Department of Periodontology and Oral Medicine, School of Stomatology, Fourth Military Medical \\ University, Xi'an 710032, P. R. China \\ 2 Department of Oral Histopathology, School of Stomatology, Fourth Military Medical University, Xi'an \\ 710032, P. R. China \\ *Corresponding author. E-mails: wzfwxy@fmmu.edu.cn or dentistcy@126.com (Z.-F.Wu) \\ Sci Pharm. 2008; 76: 689-698 \\ doi:10.3797/scipharm.0804-05 \\ Published: $\quad$ November $7^{\text {th }} 2008$ \\ Accepted: $\quad$ November $4^{\text {th }} 2008$ \\ Received: $\quad$ April $4^{\text {th }} 2008$
}

This article is available from: http://dx.doi.org/10.3797/scipharm.0804-05

(c) Chen et al; licensee Österreichische Apotheker-Verlagsgesellschaft m. b. H., Vienna, Austria.

This is an Open Access article distributed under the terms of the Creative Commons Attribution License (http://creativecommons.org/licenses/by/3.0/), which permits unrestricted use, distribution, and reproduction in any medium, provided the original work is properly cited.

\begin{abstract}
Objective: In this study, the effects of baicalin - a flavonoid purified from Scutellaria baicalensis. Georgi, Scutellaria L. - on alveolar bone resorption in rat experimental periodontitis were examined.

Method: 12 Sprague-Dawley rats (SD rats) were randomly divided into four groups: Group A1, A2, B and C. Except for Group C - the control group-, Group A1, A2 and B were used to establish the rat periodontitis model by repeat injection of Lipopolysaccharide (LPS). At the same time, Group A1 and A2 were injected with baicalin of different concentration. 9 days later, the maxillae were extracted and analyzed using micro computerized tomography (micro-CT), followed by histological analysis.

Result: Micro-CT images showed that alveolar bone resorption was severely induced around the molar by repeat injection of LPS. Treatment with high-dose baicalin $(1.0 \mu \mathrm{g} / \mathrm{ml})$ clearly recovered alveolar bone resorption, meanwhile, low-dose baicalin $(0.1 \mu \mathrm{g} / \mathrm{ml})$ showed a similar but weaker effect. Histological examination clarified that the number of osteoclast was dose dependently decreased by baicalin treatment.

Conclusion: These findings suggest that baicalin may inhibit the alveolar bone loss in periodontitis effectively.
\end{abstract}

\section{Keywords}

Baicalin • Micro-CT • Alveolar bone resorption $\bullet$ LPS $・$ Rat experimental periodontitis 


\section{Introduction}

Periodontal disease is a chronic infective disease of the periodontium caused by bacteria present in dental plaque, characterized by destruction of tooth-supported tissues including connective tissue and alveolar bone.

Alveolar bone resorption is a major problem in advanced-stage periodontitis. Much effort has been made to develop drugs for prevention and treatment of bone resorption. It has been showed that some flavonoids inhibited osteoclast differentiation and bone resorption [1-4]. Baicalin is a flavonoid purified from the medicinal plant Scutellariabaicalensi Georgi that has been used in herbal formulas to treat inflammatory diseases for thousands of years in traditional Chinese medicine. It had been reported that baicalin exhibited antibacterial, anti-inflammatory and analgesic effects [5-10]. Many scholars found that baicalin could inhibit tissue's inflammatory response through decreasing the release of TNF- $\alpha$, IL-1 $\beta$, IL- 6 and other factors which had been confirmed that might enhance osteoclast function and promote bone resorption directly or indirectly [11-13].

Lipopolysaccharide (LPS) is a component of membrane structure of gram-negative bacteria and plays an important role to trigger the inflammatory cascade in the pathogenesis of periodontitis.

Micro computerized tomography (micro-CT) has been widely used for the study of bone metabolism in animals. Micro-CT can elaborate cross-sectional tomograms of $\approx 10 \mu \mathrm{m}$ thick, and then build three dimensional images via computer. Micro-CT analysis has been used as a convenient method for the histomorphometrical study of long bones in ovariectomized rats and gene-deficient mice [14, 15].

In the present study, it was the aim to examine the effects of baicalin on alveolar bone resorption in rat experimental periodontitis by assessing morphological data obtained from micro-CT and histological sections.

\section{Experimental}

\section{Grouping and Medication}

The studies reported herein conformed to the UK Animals (scientific procedures) Act of 1986. All of the procedures used in this article have been previously described by Ramamurthy et al. and Dumitrescu et al. $[16,17]$.

Twelfe Sprague-Dawley rats (SD rats) were provided by Fourth Military Medical University Experimental Animal Center, clean-class, 10-week-old, male, weight (230 $\pm 20 \mathrm{~g}) .12$ rats were randomly divided into four groups: Group A1, A2, B and C. Group A1, A2 and B were injected with $1 \%$ Sodium Pentobarbital (25 $\mathrm{mg} / \mathrm{kg}$ body weight) to the abdominal cavity for anesthesia. Then, $15 \mu \mathrm{L}$ LPS $(1 \mathrm{mg} / \mathrm{ml})$ were injected into the bottom of gingival groove at the buccal aspect of the right maxillary second molar. One injection for every 48 hours, for four times. From the second day, the same situs of Group A1 were injected with $15 \mu \mathrm{l}$ baicalin $(1.0 \mu \mathrm{g} / \mathrm{ml})$ and Group A2 were injected with $15 \mu \mathrm{l}$ baicalin $(0.1 \mu \mathrm{g} / \mathrm{ml})$ respectively every 48 hours for four times. Group $C$ were used as the non-injected control group. 
Nine days later, the maxillae were extracted and washed with Phosphate buffered Saline (PBS) ( $\mathrm{pH} \mathrm{7.2)} \mathrm{for} \mathrm{two} \mathrm{times,} \mathrm{fixed} \mathrm{with} \mathrm{Formalin} \mathrm{(10 \% )} \mathrm{for} 24$ hours and preserved in ethanol $(70 \%)$ at $4^{\circ} \mathrm{C}$.

\section{Micro-CT}

Maxillae were scanned by micro-CT (Explore Locus, GE co., USA). The CT was set as follows: pixel size, 1024 x 1024; slice thickness, $14 \mu \mathrm{m}$; magnification, 8x; voltage, 50Kv; and electrical current, $0.1 \mathrm{~mA}$. The frontal sections were made parallel to the medial root of the second molar using a computer.

\section{Histopathology}

Maxillae samples were fixed, decalcified, embedded, sliced (the frontal sections, parallel to the medial root of the second molar, were prepared $\approx 20 \mu \mathrm{m}$ thick), and stained with hematoxylin Yihong (HE) conventionally. Osteoclast was identified when the number of nuclei was three or more than three. Three slides of each sample will be chosen and three fields of vision on each slide were selected randomly. Under a light microscope at 40x magnifications, the number of osteoclasts in every field of vision was counted.

\section{Statistical analysis}

All values were expressed as the mean \pm standard deviation $(x \pm s)$. Variance analysis with SPSS10.0 was adopted for statistical analysis. $P$ value of $<0.05$ were considered significant.

\section{Results}

\section{Micro-CT}

a

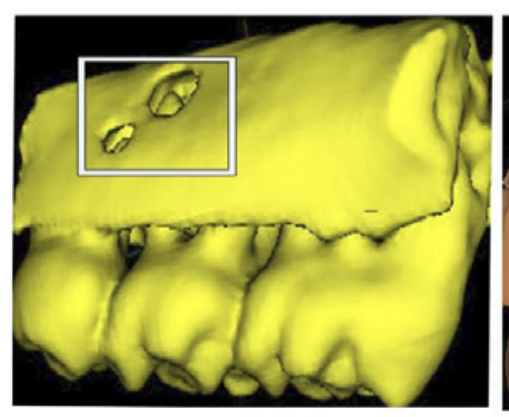

b

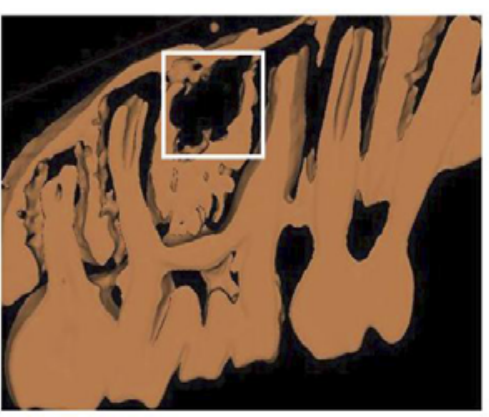

$\mathrm{c}$

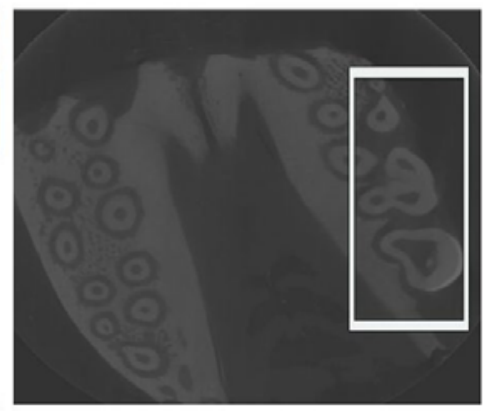

Fig. 1. The surface reconstruction image of the right maxillary of Group B(Figure 1a); Image of the root furcation of the second molar of Group B (Figure1b); Image of the whole maxilla of Group B (Figure 1c).

The images of micro-CT were shown in Fig. 1. As shown in Fig. 1a, it was the surface reconstruction image of the right maxilla of Group $B$, which exhibited obvious bone resorption on the surface of alveolar bone similar alveolar bone loss in Group B was identified below the root furcation of the right second molar of the maxilla (Fig. 1b) Fig. 1c was image of the whole maxilla of Group B. Compared with the control side, the cortex of 
the alveolar bone lost obviously in the experiment side. It was demonstrated that the rat periodontitis model was successfully established.
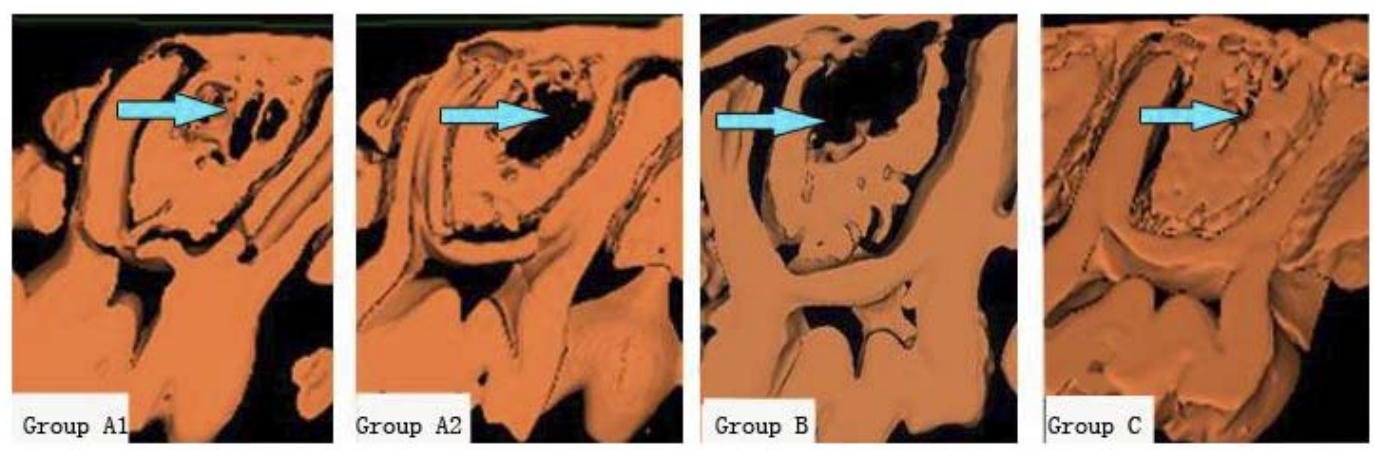

Fig. 2. The surface reconstruction image of the right maxillary second molar in each group. Region of bone resorption is shown as arrow.

Observing the images of micro-CT in each group (Fig. 2 ), region of bone resorption were shown as arrows. The degree of bone resorption from heavy to light was in the order of Group B, A2, A1 and C.
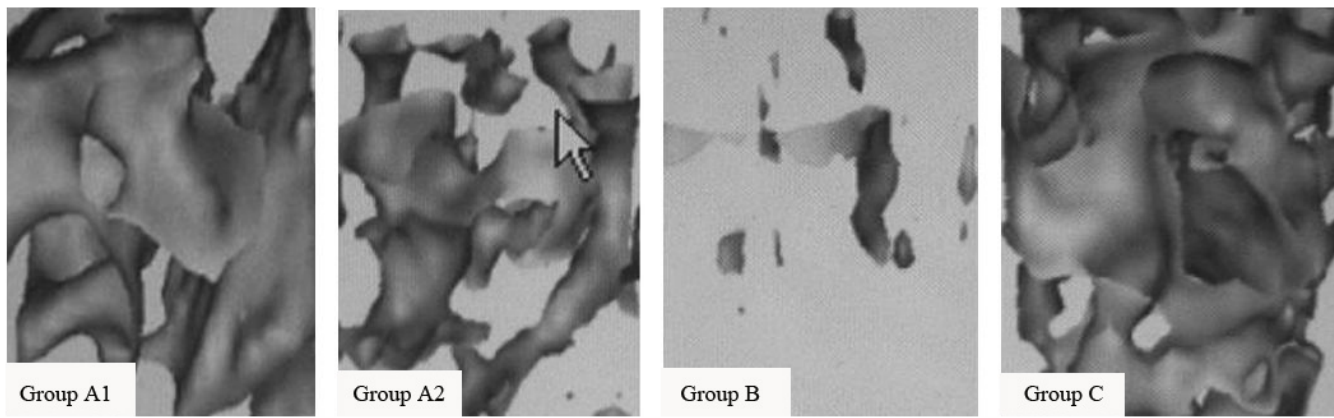

Fig. 3. The rats' trabecular bone performance in ROI in each group. ROI was confined to 2 $\mathrm{mm}^{3}$ region $5 \mathrm{~mm}$ under the root furcation of the second molar.

Semi-automatic method was used to choose the region of interest (ROI). ROI is confined to region of $2 \mathrm{~mm}^{3}$ and $5 \mathrm{~mm}$ under the root furcation of the right second molar.

It was presented the trabecular bone in ROI in each group (Fig. 3). Apparent difference in trabecular thickness and trabecular number among these groups was visualized. 
Tab. 1. Parameters of $R O I$ in each group

\begin{tabular}{llllllll}
\hline Group & $\begin{array}{c}\text { BV/TV } \\
(\%)\end{array}$ & $\begin{array}{c}\text { BS/BV } \\
\left(\mathbf{m m}^{-1}\right)\end{array}$ & $\begin{array}{c}\text { Tb.Th } \\
(\mathbf{u m})\end{array}$ & $\begin{array}{c}\text { TB.N } \\
\left(\mathbf{m m}^{-1}\right)\end{array}$ & $\begin{array}{c}\text { Tb.Sp } \\
(\mathbf{u m})\end{array}$ & SMI & $\begin{array}{c}\text { Tb.Pf } \\
\left(\mathbf{m m}^{-1}\right)\end{array}$ \\
\hline $\mathrm{A} 1$ & $36.1 \pm 2.63$ & $15.49 \pm 1.14$ & $231.25 \pm 17.21$ & $1.31 \pm 0.06$ & $613.14 \pm 20.66$ & $1.09 \pm 0.11$ & $1.66 \pm 0.11$ \\
$\mathrm{~A} 2$ & $27.38 \pm 1.89$ & $12.04 \pm 1.23$ & $210.76 \pm 9.46$ & $1.2 \pm 0.03$ & $665.48 \pm 30.8$ & $1.19 \pm 0.09$ & $2.13 \pm 0.19$ \\
$\mathrm{~B}$ & $19.96 \pm 1.81$ & $7.68 \pm 1.45$ & $145.28 \pm 2.91$ & $1.13 \pm 0.15$ & $728.46 \pm 18.23$ & $1.13 \pm 0.22$ & $4.25 \pm 0.34$ \\
$\mathrm{C}$ & $44.36 \pm 1.09$ & $18.65 \pm 2.1$ & $268.52 \pm 17.03$ & $1.46 \pm 0.11$ & $589.26 \pm 21.18$ & $0.98 \pm 0.23$ & $1.28 \pm 0.09$ \\
$\mathrm{P}^{\mathrm{a}}$ & $<0.01$ & $<0.01$ & $<0.01$ & $<0.01$ & $<0.01$ & $>0.05$ & $<0.01$ \\
\hline
\end{tabular}

${ }^{\mathrm{a}} \mathrm{P}$ value is the difference of parameters between groups.

Micview 3D reconstruction processing software and ABA special skeletal analysis software were used to obtain and analyze the three-dimensional parameters of the maxillae. The three-dimensional parameters included relative bone volume (BV / TV); ratio of bone surface area to bone volume (BS / BV); trabecular bone thickness (Tb Th); trabecular bone number (Tb $\mathrm{N}$ ); trabecular bone space (Tb $\mathrm{Sp}$ ); trabecular bone structure model index (SMI, which reports the structure model index) and trabecular bone model factor (Tb Pf, which is a measure of the connectivity of a trabecular structure. The value is less, the connectivity is better).

As shown in Table 1, 3D parameters of $\mathrm{ROI}$ in each group were measured and analyzed. It was found that: The data of BV / TV, BS / BV, Tb Th and Tb N were found to follow a diminishing order GroupC $>\mathrm{A} 1>\mathrm{A} 2>\mathrm{B}(\mathrm{P}<0.01)$. The data of Tb $\mathrm{Sp}$ and $\mathrm{Tb}$ Pf were found to follow the converse order GroupC $<A 1<A 2<B(P<0.01)$. There was no statistical significance in the difference of SMI between these groups $(P>0.05)$. SMI gives information about the curvature of the surface, and estimates how "plate-like" or "rod-like" a trabecular structure is. The value of SMI revealed that there were mainly "plate-like" bone within the $2 \mathrm{~mm}^{3}$ volume region $5 \mathrm{~mm}$ below the root furcation of second molar. If the sample size were enlarged, more reliable conclusions might be obtained.

\section{Histopathology}

It showed osteoclast under 10x and 40x magnification (Fig. 4). Osteoclasts are marked as arrows.
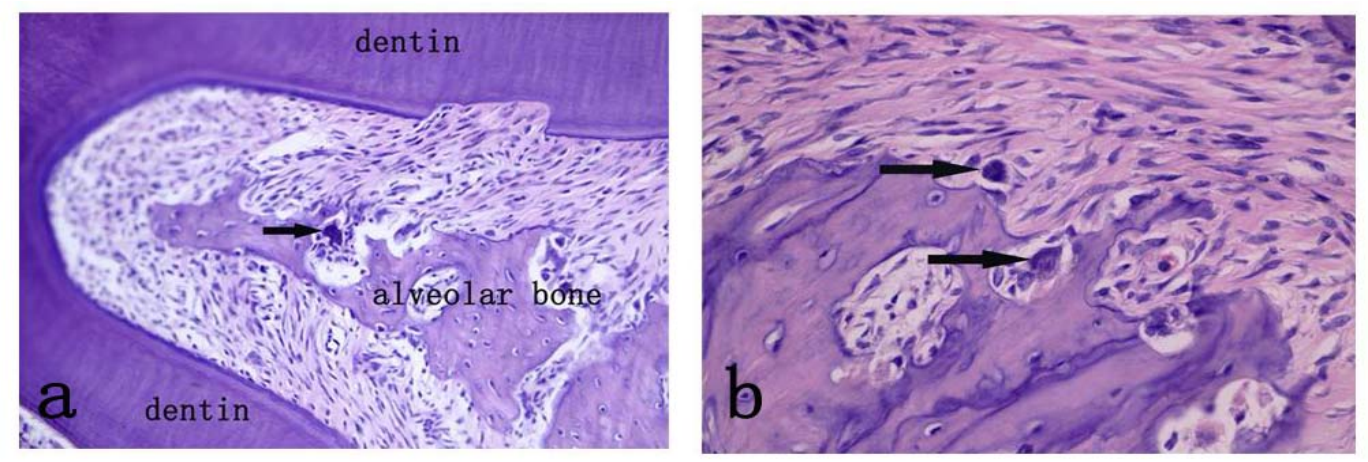

Fig. 4 . Osteoclast under10x (Fig. 4a), 40x (Fig. 4b) magnification 


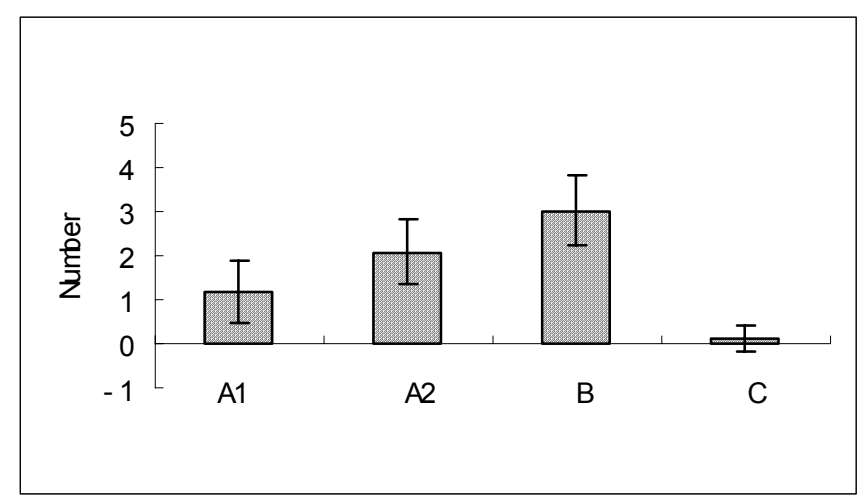

Fig. 5. The number of osteoclasts in each group

Fig. 5 showed a decreased number of osteoclasts from group $B, A 2, A 1$ to $C$, and statistical significance were found between these groups $(P<0.01)$.

\section{Discussion}

Experimental animal models have been used to clarify the pathogenesis of periodontal diseases and develop new periodontal therapy [18, 19]. Intragingival injection of LPS have been accepted as useful experimental models of periodontitis with alveolar bone resorption. Dumitrescu et al. [20] reported that periodontal inflammation was induced by a single injection of 10 microg liposaccharide (LPS) in 1 microl saline into rat mandibular gingiva at the buccomesial aspect of the second molar. 7 and 10 days later, LPS injection resulted in a significant gingival and periodontal inflammation with inflammatory infiltrate, apical migration of the junctional epithelium, interdental bone loss, and activation of osteoclasts at the site of injection. It indicated that intragingival injection of LPS in the rat provides an easily induced reproducible experimental model of periodontal inflammation that reiterates features of human disease. Using this experimental model, we were able to evaluate the effect of baicalin in periodontitis.

Micro-CT has been widly used in the study of bone metabolism. Previous reports showed that micro-CT is an effective method for histomorphometrical analysis of long bone in ovariectomized rats and gene-deficient mice $[14,15,21]$. In dental science, including periodontology, few studies employ micro-CT, whereas micro-CT has been more commonly used in endodontic research [22, 23]. To date, analysis of X-ray photographs and histological sections of alveolar bone have been performed as conventional methods in periodontal research $[24,25]$. As the periodontal tissue structure is complicated, many steps are necessary to produce histological sections. Micro-CT can produce accurate figures of hard periodontal tissues by constructing three-dimensional images via computer. In this study, we were able to obtain clear sections of the rat molar area using micro-CT, indicating that micro-CT is useful for analyzing alveolar bone.

Previous reports suggested that baicalin could inhibit tissue's inflammatory response through decreasing the release of TNF- $\alpha$, IL-1 $\beta$, IL- 6 and other factors which had been confirmed that might enhance osteoclast function and promote bone resorption directly or indirectly [11-13]. Wang GF [26] showed that the expression of RANKL mRNA stimulated by IL-1 $\beta$ was inhibited by baicalin after being treated for $12 \mathrm{~h}$ and the inhibition reached its 
maximum at $48 \mathrm{~h}$. In this study, our histological finding that the number of osteoclast was dose dependently decreased by baicalin treatment. Therefore, it is suggested that baicalin coule be effective for the inhibition of alveolar bone loss.

Analysis using micro-CT showed the tendency to recover alveolar bone in Group A1and A2. The data of BV / TV, BS / BV, Tb Th and Tb N were found to follow a diminishing order GroupC $>A 1>A 2>B(P<0.01)$. It demonstrated that LPS could reduce BV / TV, BS / BV, $\mathrm{Tb} \mathrm{Th}$ and $\mathrm{Tb} \mathrm{N}$ of alveolar bone significantly while baicalin could inhibit the decrease of BV / TV, BS / BV, Tb Th and Tb N of alveolar bone induced by LPS and reduce the damage to trabecular bone connectivity. The data of Tb Sp and Tb Pf were found to follow the converse order GroupC $<A 1<A 2<B(P<0.01)$. It showed that LPS could enlarge the trabecular bone space significantly and make the connectivity worse. However, baicalin could diminish the increase of trabecular bone space and make the connectivity better. These results support our hislogical finding that treatment with high-dose baicalin $(1.0 \mu \mathrm{g} /$ $\mathrm{ml})$ clearly recovered alveolar bone resorption, meanwhile, low-dose baicalin $(0.1 \mu \mathrm{g} / \mathrm{ml})$ showed a similar but weaker effect.

In conclusion, we clarified the inhibition effect of baicalin on alveolar bone resorption after LPS-induced rat periodontitis. It could be expected that baicalin were applied in the prevention and treatment of alveolar bone loss in periodontitis.

\section{Authors' Statements}

\section{Competing Interests}

The authors declare no conflict of interest.

\section{Animal Rights}

The institutional and (inter)national guide for the care and use of laboratory animals was followed. See the experimental part for details.

\section{References}

[1] Nakagawa H, Wachi M, Woo JT, Kato M, Kasai S, Takahashi F, Lee IS, Nagai K.

Fenton reaction is primarily involved in a mechanism of (-)-epigallocatechin-3-gallate to induce osteoclastic cell death.

Biochem Biophys Res Commun. 2002; 292: 94-101. doi:10.1006/bbrc.2002.6622

[2] Wattel A, Kamel S, Mentaverri R, Lorget F, Prouillet C, Petit JP, Fardelonne P, Brazier M. Potent inhibitory effect of naturally occurring flavonoids quercetin and kaempferol on in vitro osteoclastic bone resorption.

Biochem Pharmacol. 2003; 65: 35-42. doi:10.1016/S0006-2952(02)01445-4

[3] Woo JT, Nakagawa H, Notoya M, Yonezawa T, Udagawa N, Lee IS, Ohnishi M, Hagiwara H, Nagai K. Quercetin suppresses bone resorption by inhibiting the differentiation and activation of osteoclasts. Biol Pharm Bull. 2004; 27: 504-509. doi:10.1248/bpb.27.504 
[4] Wattel A, Kamel S, Prouillet C, Petit JP, Lorget F, Offord E, Brazier M.

Flavonoid quercetin decreases osteoclastic differentiation induced by RANKL via a mechanism involving NF kappa B and AP-1.

J Cell Biochem. 2004; 92: 285-295.

doi:10.1002/jcb.20071

[5] Ng TB, Ling JM, Wang ZT, Cai JN, Xu GJ

Examination of coumarins, flavonoids and polysaccharopeptide for antibacterial activity.

Gen Pharmacol. 1996; 27: 1237-1240.

doi:10.1016/0306-3623(95)02143-4

[6] Chung CP, Park JB, Bae KH.

Pharmacological effects of methanolic extract from the root of Scutellaria baicalensis and its flavonoids on human gingival fibroblast.

Planta Med. 1995; 61: 150-153.

doi:10.1055/s-2006-958036

[7] Butenko IG, Gladtchenko SV, Galushko SV.

Anti-inflammatory properties and inhibition of leukotriene $\mathrm{C} 4$ biosynthesis in vitro by flavonoid baicalein from Scutellaria baicalensis georgy roots.

Inflamm Res. 1993; 39 : C49-C51.

doi:10.1007/BF01972717

[8] Krakauer T, Li BQ, Young HA.

The flavonoid baicalin inhibits superantigen-induced inflammatory cytokines and chemokines.

FEBS Lett. 2001; 500: 52-55.

doi:10.1016/S0014-5793(01)02584-4

[9] Chou TC, Chang LP, Li CY, Wong CS, Yang SP.

The antiinflammatory and analgesic effects of baicalin in carrageenan-evoked thermal hyperalgesia. Anesth Analg. 2003;97:1724-1729.

doi:10.1213/01.ANE.0000087066.71572.3F

[10] Li BQ, Fu T, Gong WH, Dunlop N, Kung H, Yan Y, Kang J, Wang JM.

The flavonoid baicalin exhibits anti-inflammatory activity by binding to chemokines.

Immunopharmacology. 2000; 49: 295-306.

doi:10.1016/S0162-3109(00)00244-7

[11] Lin CC, Shieh DE.

The anti-inflammatory activity of Scutellaria rivularis extracts and its active components, baicalin, baicalein and wogonin.

Am J Chin Med. 1996; 24: 31-36.

doi:10.1142/S0192415X96000050

[12] Chou TC, Chang LP, Li CY, Wong CS, Yang SP.

The antiinflammatory and analgesic effects of baicalin in carrageenan-evoked thermal hyperalgesia. Anesth Analg. 2003; 97: 1724-1729.

doi:10.1213/01.ANE.0000087066.71572.3F

[13] Chung CP, Park JB, Bae KH.

Pharmacological effects of methanolic extract from the root of Scutellaria baicalensis and its flavonoids on human gingival fibroblast.

Planta Med. 1995; 61: 150-153.

doi:10.1055/s-2006-958036

[14] Montero A, Okada Y, Tomita M, Ito M, Tsurukami H, Nakamura T, Doetschman T, Coffin JD, Hurley MM.

Disruption of the fibroblast growth factor-2 gene results in decreased bone mass and bone formation. J Clin Invest. 2000; 105: 1085-1093.

doi:10.1172/JCl8641 
[15] Gittens SA, Wohl GR, Zernicke RF, Matyas JR, Morley P, Uludag H.

Systemic bone formation with weekly PTH administration in ovariectomized rats.

J Pharm Pharm Sci. 2004; 7: 27-37.

PMid.15144732

[16] Ramamurthy NS, Rifkin BR, Greenwald RA, Xu JW, Liu Y, Turner G, Golub LM, Vernillo AT. Inhibition of matrix metalloproteinase-mediated periodontal bone loss in rats: a comparison of 6 chemically modified tetracyclines.

J Periodontol. 2002; 73: 726-734.

doi:10.1902/jop.2002.73.7.726

[17] Dumitrescu AL, Abd-El-Aleem S, Morales-Aza B, Donaldson LF.

A model of periodontitis in the rat: effect of lipopolysaccharide on bone resorption, osteoclast activity, and local peptidergic innervation.

J Clin Periodontol. 2004; 31: 596-603.

doi:10.1111/j.1600-051X.2004.00528.x

[18] Baker PJ, Dixon M, Evans RT, Dufour L, Johnson E, Roopenian DC.

$\mathrm{CD} 4(+)$ Tcells and the proinflammatory cytokines gamma interferon and interleukin- 6 contribute to alveolar bone loss in mice.

Infect Immun. 1999; 67: 2804-2809.

PMid:10338484

[19] Teng YT, Nguyen H, Gao X, Kong YY, Gorczynski RM, Singh B, Ellen RP, Penninger JM. Functional human T-cell immunity and osteoprotegerin ligand control alveolar bone destruction in periodontal infection.

J Clin Invest. 2000; 106: R59-R67.

PMid:10995794

[20] Dumitrescu AL, Abd-El-Aleem S, Morales-Aza B, Donaldson LF.

A model of periodontitis in the rat: effect of lipopolysaccharide on bone resorption, osteoclast activity, and local peptidergic innervation.

J Clin Periodontol. 2004; 31: 596-603.

doi:10.1111/j.1600-051X.2004.00528.x

[21] Ishijima M, Tsuji K, Rittling SR, Yamashita T, Kurosawa H, Denhardt DT, Nifuji A, Noda M Resistance to unloading-induced three-dimensional bone loss in osteopontin-deficient mice.

J Bone Miner Res. 2002; 17: 661-667.

doi:10.1359/jbmr.2002.17.4.661

[22] Balto K, White R, Mueller R, Stashenko P.

A mouse model of inflammatory root resorption induced by pulpal infection.

Oral Surg Oral Med Oral Pathol Oral Radiol Endod. 2002; 93: 461-468.

doi:10.1067/moe.2002.122641

[23] Tanaka M, Toyooka E, Kohno S, Ozawa H, Ejiri S.

Long-term changes in trabecular structure of aged rat alveolar bone after ovariectomy.

Oral Surg Oral Med Oral Pathol Oral Radiol Endod. 2003; 95: 495-502.

doi:10.1067/moe.2003.135

[24] Mitsuta T, Horiuchi $\mathrm{H}$, Shinoda $\mathrm{H}$.

Effects of topical administration of clodronate on alveolar bone resorption in rats with experimental periodontitis.

J Periodontol. 2002; 73: 479-486.

doi:10.1902/jop.2002.73.5.479

[25] Marques MR, da Silva MA, Manzi FR, Cesar Neto JB, Nociti FH Jr, Barros SP.

Effect of intermittent PTH administration in the periodontitis-associated bone loss in ovariectomized rats.

Arch Oral Biol. 2005; 50: 421-429.

doi:10.1016/j.archoralbio.2004.08.014 
[26] Wang GF, Wu ZF, Wan L, Wang QT, Chen FM.

Influence of baicalin on the expression of receptor activator of nuclear factor-kappaB ligand in cultured human periodontal ligament cells.

Pharmacology. 2006; 77: 71-77.

doi:10.1159/000092853 